\title{
Evaluation of Laparoscopic Appendectomy in Complicated Appendicitis
}

\author{
Ahmed Abd El Aal Sultan ${ }^{1}$ MD, Ahmed Abd Elbaset Elsayed ${ }^{1 *}$ M.B.B.Ch and Magdy Salah El-Din \\ Hussain ${ }^{1}$ MD.
}

\begin{abstract}
* Corresponding Author:
Ahmed Abd Elbaset Elsayed

drahmednour2014@gmail.com

Received for publication July 5 , 2020; accepted September 20, 2020; published online September 20, 2020.
\end{abstract}

Copyright 2020 The Authors published by Al-Azhar University, Faculty of Medicine, Cairo, Egypt. All rights reserved. This an openaccess article distributed under the legal terms, where it is permissible to download and share the work provided it is properly cited. The work cannot be changed in any way or used commercially.

\section{doi:}

\subsection{8/aimj.2020.31153.1243}

1 General Surgery Department, Faculty of Medicine, Al-Azhar University, Cairo, Egypt.

\begin{abstract}
Background: The role of laparoscopy in the treatment of complicated appendicitis is increasing.

Objective: The study goals to assess the role of laparoscopy in complicated appendicitis.

Patient and Methods: This prospective case series study involved 40 patients with complicated appendicitis who submitted to laparoscopic appendectomy and were assessed concerning operative time, the postoperative outcome as regard analgesia use, duration of hospital stay, back to usual oral feeding, and postoperative complications in the Department of General Surgery at Al Hussein University Hospital and Ahmed Maher Teaching Hospital, from September 2019 to May 2020.

Results: 40 patients submitted to laparoscopic appendectomy for complicated appendicitis. The mean age of all considered patients was $28.4 \pm 9.7$ years with a minimum age of 18 years and maximum age of 53 years, there were 14 males (35\%) and 26 females $(65 \%)$ in the considered patients. Of the 40 patients, perforated appendix cases were 18 , gangrenous appendix cases were 10, appendicular abscess cases were 8 and appendicular mass cases were 4 cases. Conversion to open technique was done in 2 cases (5\%), postoperative hospital stay was two days in 10 patients (25\%), 3 days in 14 patients (35\%), 4 days in 12 patients $(30 \%)$ more than 5 days in 4 patients $(10 \%)$ and 2 patients had prolonged stay (converted to open surgery patients) and postoperative complications in 12 cases $(30 \%)$ as fever, intra-abdominal collection, ileus and wound infection.

Conclusion: Laparoscopic appendectomy remains a safe and efficient technique in the treatment of complicated appendicitis.

Keywords: Appendicitis; Complicated appendicitis; Laparoscopic appendectomy.

Authorship: All authors have a substantial contribution to the article.

Disclosure: The authors have no financial interest to declare in relation to the content of this article. The Article Processing Charge was paid for by the authors.
\end{abstract}

\section{INTRODUCTION}

Acute appendicitis remains one of the furthermost common causes of acute abdominal pain with a prevalence of 1.17 per 1000 and a lifetime risk of approximately $7 \%{ }^{1} \quad$ The delay in diagnosis may lead to difficulties like an appendicular abscess, mass, gangrene, perforation, and peritonitis. ${ }^{2}$ The benefits of laparoscopic technique over conventional

open the technique contains shorter hospital stay, earlier return to usual activity, reduced pain, and better cosmosis. ${ }^{3}$ Laparoscopic appendectomy has rapidly been established in recent years. Since Semm issued the first complete amputation of the appendix through laparoscopic operation in 1983 and Schreiber did the first laparoscopic appendectomy in a patient with acute appendicitis in 1987, laparoscopic appendectomy has been involved in nearly all hospitals international as the traditional technique in emergency departments. ${ }^{4}$ Benefits of laparoscopic appendectomy consist of a quick return to usual 
patient's activity, and a better cosmetic result. The tendency to reduced patient illness after surgery has allowed the development of procedures requiring progressively less invasive contact to the operating field. ${ }^{5}$ Better access and the good imagining of the peritoneal cavity through small openings give laparoscopic appendectomy benefits when compared with an open approach. So, complicated appendicitis is well managed by laparoscopic technique. ${ }^{6}$

\section{AIM OF THE WORK}

The study goals to assess the role of laparoscopy in complicated appendicitis concerning operative time, intra-operative problems, hospital stay, analgesia use, return to usual oral feeding, and postoperative hazards.

\section{PATIENT AND METHODS}

Forty patients with suspected complicated acute appendicitis were admitted to the emergency room in Al-Hussein university hospital and Ahmed Maher Teaching Hospital, from September 2019 to May 2020. The suspicion of acute appendicitis which may complicates was succeeded by the next criteria: History of existing illness further than 3 days, Fever further than $39^{\circ} \mathrm{C}$. and Total leukocytic count further than 11000. Signs of complications in investigations are like as in ultrasound or CT image.

All patients were subjected to: History taking from the patient with a special alarm about the time of initial pain, General examination to omit general difficulties contraindicating laparoscopy.

Local examination is mandatory to make sure the existence of appendicitis and if any mass can be palpated. Laboratory investigations as CBC, liver, and kidney function tests, PT, PTT, and INR were done with a special concern about total leukocytic count and differential leukocytic count.

Radiological investigations are done as abdominal Ultrasonography.

Inclusion criteria: after diagnostic laparoscopy during the technique were Appendicular abscess, Nonpalpable mass, Gangrenous appendix, Perforated appendicitis, Appendicitis with peritonitis and Appendicitis with extensive adhesions.

Exclusion criteria were; Laparoscopy for uncomplicated appendicitis, suspicion of malignancy, Pregnant with Palpable appendicular mass.

\section{Surgical procedure.}

Preoperative antibiotics and intravenous fluids were administrated. Under general anesthesia with endotracheal intubation and the patient in the supine position, pneumo-peritoneum via either the Verrus needle or Hasson open method was achieved. Three ports were used, the first port was $10 \mathrm{~mm}$ periumbilical port for the camera and the second port was $5 \mathrm{~mm}$ in the suprapubic area in the midline and the latest one was another $10 \mathrm{~mm}$ port between the previous two ports. The location of the appendix was explored to identify the type of complicated appendix. Control of the mesoappendix was done either by electro-cautery or clips or both while control of the base of the appendix was done by either end loop ligature or intra-corporeal sutures or clips. Retrieval of the appendix was done either by the endo-catch bag or through the $10 \mathrm{~mm}$ port. Peritoneal wash using saline was done until the wash fluid converted into clear, intra-peritoneal tube drain was left either in an appendicular bed or the pelvis. Statistical analysis.

Statistical Study Categorical variables existed as a number (ratio). All data were evaluated using SPSS 22.0 for windows (SPSS Inc., Chicago, IL, USA).

\section{RESULTS}

The study involved 40 patients of adult males and females. The mean age of the considered patients was $28.4 \pm 9.7$ years with a range among 18 and 53 years. Out of 40 patients, $26(65 \%)$ patients were females and $14(35 \%)$ patients were males. (Table 1$)$.

All 40 patients submitted to diagnostic laparoscopy at first and intra-operative outcome were as following, 18 patients $(45 \%)$ were perforated appendicitis (PA), 10 patients (25\%) were gangrenous appendicitis, 8 patients $(20 \%)$ were appendicular abscess and 4 patients (10\%) were appendicular mass. (Table 2). The mean operating time of all considered patients was $51.7 \pm 18.5 \mathrm{~min}$ with a minimum time of 40 minutes and a maximum time of 120 minutes (Table 3).

There were 38 patients (95\%) who continued on the laparoscopic technique while there were only 2 patients $(5 \%)$ converted to open technique. One $(2.5 \%)$ case with appendicular mass was converted to open method by midline incision due to extensive adhesions, and one $(2.5 \%)$ case with a gangrenous appendix was converted to open method by lower midline incision due to gangrenous base with friable cecum that required trimming of the base with closure by interrupted suture and application of only omental patch (Table 4). Concerning return to oral feeding in all considered patients, 14 patients (35\%) resumed on the same day of operation, 20 patients $(50 \%)$ resumed on the $1^{\text {st }}$ postoperative day and 6 patients $(15 \%)$ resumed on the $2^{\text {nd }}$ postoperative day (Table 5).

The postoperative hospital stay was 2 days in 10 patients (25\%), 3 days in 14 patients (35\%), 4 days in 12 patients $(30 \%)$, further than 5 days in 4 patients $(10 \%), 2$ patients of these cases had prolonged stay (converted to open surgery patients) (Table 6). Postoperative follow up of 40 patients revealed, Fever further than $38^{\circ} \mathrm{c}$ with collection on follow-up ultrasound in 2 patients $(5 \%)$, Fever further than $38^{\circ} \mathrm{C}$ without collection on follow-up ultrasound in 3 patients $(7.5 \%)$, postoperative ileus in 2 patients $(5 \%)$, wound seroma in 3 patients $(7.5 \%)$, wound infected seroma and infection in 2 patients $(5 \%)$ while there were no complications in 28 patients (70\%) (Table 7). 


\begin{tabular}{|c|c|c|c|}
\hline & & & $\begin{array}{l}\text { Studied patients } \\
\qquad(\mathrm{N}=40)\end{array}$ \\
\hline \multirow{2}{*}{ Age (years) } & Mean \pm SD & & $28.4 \pm 9.7$ \\
\hline & Min - Max & & $18-53$ \\
\hline \multirow{2}{*}{ Sex } & Male & 14 & $35 \%$ \\
\hline & Female & 26 & $65 \%$ \\
\hline
\end{tabular}

Table 1: Demographic data of studied patients.

\begin{tabular}{|c|c|c|c|}
\hline & & \multicolumn{2}{|c|}{$\begin{array}{l}\text { Studied patients } \\
\qquad(\mathrm{N}=40)\end{array}$} \\
\hline \multirow{4}{*}{ Intraoperative findings } & Appendicular abscess & 8 & $20 \%$ \\
\hline & Appendicular mass & 4 & $10 \%$ \\
\hline & Gangrenous appendicitis & 10 & $25 \%$ \\
\hline & Perforated appendicitis & 18 & $45 \%$ \\
\hline
\end{tabular}

Table 2: Intra-operative findings of all studied patients.

\begin{tabular}{|c|c|c|}
\hline & & $\begin{array}{l}\text { Studied patients } \\
\qquad(\mathrm{N}=40)\end{array}$ \\
\hline \multirow{2}{*}{ Operative time (min) } & Mean \pm SD & $51.7 \pm 18.5$ \\
\hline & Min - Max & $40-120$ \\
\hline
\end{tabular}

Table 3: Description of operative time in all studied patients.

\begin{tabular}{|c|c|c|c|}
\hline & & & \\
\hline \multirow{2}{*}{ Conversion to open procedure } & No & 38 & $95 \%$ \\
\hline & Yes & 2 & $5 \%$ \\
\hline
\end{tabular}

Table 4: Conversion to open procedure in all studied patients. 


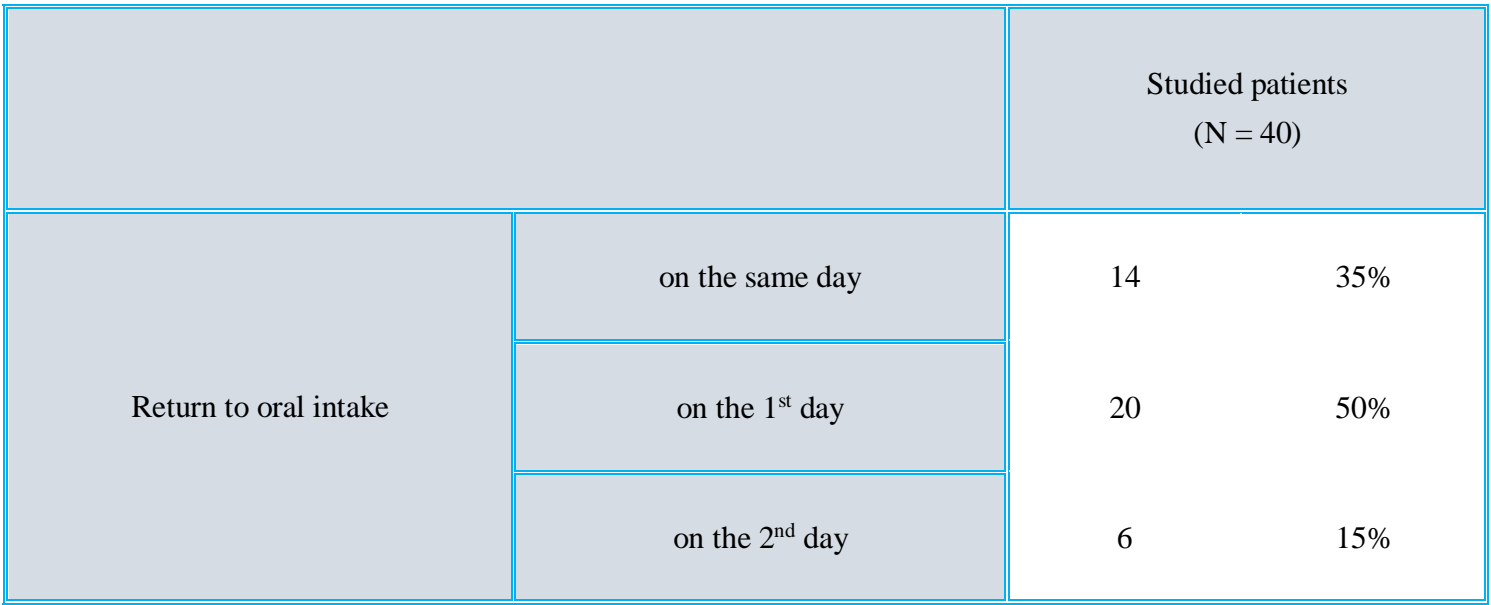

Table 5: Return to oral intake in all studied patients.

\begin{tabular}{|c|c|c|c|}
\hline & & & \\
\hline \multirow{4}{*}{$\begin{array}{l}\text { Duration of hospital stay } \\
\text { (days) }\end{array}$} & 2 days & 10 & $25 \%$ \\
\hline & 3 days & 14 & $35 \%$ \\
\hline & 4 days & 12 & $30 \%$ \\
\hline & $\geq 5$ days & 4 & $10 \%$ \\
\hline
\end{tabular}

Table 6: Duration of hospital stay in all studied patients.

\begin{tabular}{|c|c|c|c|}
\hline & & $\begin{array}{l}\text { Stud } \\
\text { (N) }\end{array}$ & \\
\hline \multirow{6}{*}{ Postoperative complications } & No complications & 28 & $70 \%$ \\
\hline & Fever $>38$ with collection on U/S & 2 & $5 \%$ \\
\hline & Fever $>38$ without collection on U/S & 3 & $7.5 \%$ \\
\hline & Post-operative ileus & 2 & $5 \%$ \\
\hline & Wound seroma & 3 & $7.5 \%$ \\
\hline & Wound infected seroma and infection & 2 & $5 \%$ \\
\hline
\end{tabular}

Table 7: Postoperative complications in all studied patients.

\section{DISCUSSION}

Recently numerous studies show that laparoscopic appendectomy provides significant advantages over the open approach, containing a shorter hospital stay, fewer postoperative pain, quicker postoperative recovery, and less complication frequency. ${ }^{7}$ there are several retrospective and uncontrolled studies of laparoscopic appendectomy (LA), as well as numerous prospective randomized studies available up to now. While most of those have determined that the laparoscopic procedure is approximately as good as the open approach, there has been considerable debate on whether LA is superior or not. ${ }^{8}$ Increased practice of surgeons and nursing 
team definitely reduced the operating time. ${ }^{9}$ In contrast to the general confidence that conversion depends on the surgeon practice, we expect that intra-operative conditions are the most cause to convert. Within the present study, we reported 2 cases of intra-operative difficulties, one case with appendicular mass was converted to an open approach by midline incision due to extensive adhesions, and another case with a gangrenous appendix was converted to open approach by lower midline incision due to gangrenous base with friable cecum.

Our outcomes show that the duration of hospitalization was considerably shorter in the LA, and this is reliable with the study of some studies. ${ }^{10}$ Postoperative pain was evaluated by the patient needing non-steroidal antiinflammatory intramuscular injection which is effective. Also, to reduce shoulder pain from remaining gas irritation, the draw of $\mathrm{CO} 2$ from the right subphrenic space and low-pressure pneumo-peritoneum were performed in all cases in addition to least tissue handling and trauma, which also donates to decreasing pain sensation. ${ }^{11}$

In Ansari et al, out of 103 patients who were effectively operated laparoscopically, 21 patients established minor complications such as fever in 11 $(10.67 \%)$ patients, $5(4.85 \%)$ patients developed postoperative ileus that postponed their start of oral feeding and $5(4.85 \%)$ patients developed port site infection. There remained no cases of postoperative intestinal obstruction and no mortality. ${ }^{12}$ the decrease of wound infection is a significant benefit of LA. The occurrence of wound infection is higher in OA relatively because the infected appendix is retrieved from the abdominal cavity directly via the wound, whereas in LA it is removed through a port. In addition, the port-site wounds in LA are minor compared to the major wounds of OA. ${ }^{13}$

We intended to find predictive issues of Intraabdominal abscess development complication in laparoscopic appendectomy. We detected that obesity, leukocytosis more than $20.000 / \mathrm{mm} 3$, perforated appendicitis, and extended operating time were associated with the development of a postoperative intra-abdominal abscess. ${ }^{14}$ minimally invasive surgical procedure is progressively established in the treatment of surgical emergencies. Nevertheless, in 2002 laparoscopic appendectomy (LA) was tested by a systematic assessment which revealed an increased frequency of IAA near threefold compared with open appendectomy (OA).

Possible causes imagined for this variation are that the infected substances may spread all over the abdominal cavity during pneumo-peritoneum or that as in the OA, the appendix is amputated outside the abdominal cavity and the base is inverted after separation, the incidence of intraperitoneal infection would be lesser. ${ }^{15}$ Asarias et al. listed that IAA is fivefold extra common with complicated appendicitis and measured increasing age as an expected feature. ${ }^{16}$ Horvath et al. accused the usage of Roeder knot, extreme wash, and the Trendelenburg's position for the greater frequency of IAA after LA in perforated appendicitis. ${ }^{17}$ while Gupta et al. blamed aggressive handling of the diseased appendix and extreme irrigation to increase infectious problems. ${ }^{18}$ Definite operative concerns were taken in mind to reduce the occurrence of intra-abdominal abscess: Firstly, low-pressure pneumo-peritoneum restricts bacterial translocations to blood flow. Secondly, the draw of pus directly at the beginning of the technique. Thirdly, widespread adhesiolysis, to prevent disappeared pockets of pus. Fourthly, suction irrigation to extract infected fluid until becomes clear and finally sufficient drainage by numerous drains. ${ }^{19}$

In the present study, 2 cases (5\%) established intraabdominal abscess, one of them underwent ultrasoundguided drainage by pigtail, and the other case was a small collection underwent conservative management on antibiotic course according to culture and sensitivity. In this study, the IAA frequency was reduced. A related report has been recent. ${ }^{20}$

\section{CONCLUSION}

This study has proved that laparoscopic appendectomy remains a safe and efficient approach in the treatment of complicated appendicitis. It resulted in a short hospital stay and low conversion frequency. It decreases the risk of postoperative infections.

\section{REFERENCES}

1. Musbahi A, Rudd D, Dordea M, Gopinath B, and Kurup V. Comparison of the use of Alvarado and AIR scores as an adjunct to the clinical diagnosis of acute appendicitis in the pediatric population. World Journal of Pediatric Surgery. 2019 ; 2(2):e000040.

2. Mwachaka P, El-busaidy H, Sinkeet S, and Ogeng'o J. Variations in the position and length of the vermiform appendix in a black kenyan population. International Scholarly Research Notices. 2014; 2014.

3. Sauerland S, Jaschinski T, and Neugebauer EA. Laparoscopic versus open surgery for suspected appendicitis. Cochrane Database of Systematic Reviews. 2010(10).

4. Sorate Y, Joshi D, and Pawar S. A Prospective Study of Laparoscopic Appendicectomy for the Treatment of Acute Appendicitis. MVP Journal of Medical Science. 2018 Aug 17;5(1):21-5.

5. Frutos MD, Abrisqueta J, Lujan J, Abellan I, and Parrilla P. Randomized prospective study to compare laparoscopic appendectomy versus umbilical singleincision appendectomy. Annals of surgery. 2013; 257(3):413-8.

6. Garg CP, Vaidya BB, and Chengalath MM. Efficacy of laparoscopy in complicated appendicitis. International journal of surgery. 2009; 7(3):250-2.

7. Mandrioli M, Inaba K, Piccinini A, Biscardi A, Sartelli M, Agresta F, Catena F, Cirocchi R, Jovine E, Tugnoli G and Di Saverio S. Advances in laparoscopy for acute care surgery and trauma. World journal of gastroenterology. 2016; 14 (2):668.

8. Katkhouda N, Mason RJ, Towfigh S, Gevorgyan A and Essani R. Laparoscopic versus open appendectomy: a prospective randomized double-blind study. Annals of surgery. 2005; 242(3):439. 
9. Thomson JE, Kruger D, Jann-Kruger C, et al. Laparoscopic versus open surgery for complicated appendicitis: a randomized controlled trial to prove safety. Surgical endoscopy. 2015; 29 (7):2027-32.

10. Shimoda M, Maruyama T, Nishida K, Suzuki K, et al. Comparison of clinical outcome of laparoscopic versus open appendectomy, single center experience. Heliyon. 2018; 1: 4(5):e00635.

11. Sauerland S, Jaschinski T, and Neugebauer EA. Laparoscopic versus open surgery for suspected appendicitis. Cochrane Database of Systematic Reviews. 2010 (10).

12. Ansari IA, Gedam BS, Shah Y, Kale VB and Bansod PY. Laparoscopic appendectomy in acute appendicitis with or without complication. Inter $J$ Biomed Advan Res. 2015; 6(3):275-9.

13. Li X, Zhang J, Sang L, Zhang $W$, et al Laparoscopic versus conventional appendectomy-a meta-analysis of randomized controlled trials. $B M C$ gastroenterology. 2010; 10 (1):129.

14. Schlottmann F, Sadava EE, Peña ME and Rotholtz NA. Laparoscopic appendectomy: risk factors for postoperative intraabdominal abscess. World journal of surgery. 2017; 41(5):1254-8.
15. Sauerland S, Jaschinski $T$ and Neugebauer EA. Laparoscopic versus open surgery for suspected appendicitis. Cochrane Database of Systematic Reviews. 2010 (10).

16. Asarias JR, Schlussel AT, Cafasso DE, et al. Incidence of postoperative intraabdominal abscesses in open versus laparoscopic appendectomies. Surgical endoscopy. 2011; 25(8):2678-83.

17. Horvath $\mathrm{P}$, Lange J, Bachmann $\mathrm{R}$, et al. Comparison of clinical outcome of laparoscopic versus open appendectomy for complicated appendicitis. Surgical endoscopy. 2017; 31(1):199-205.

18. Gupta R, Sample C, Bamehriz F and Birch DW. Infectious complications following laparoscopic appendectomy. Canadian journal of surgery. 2006; 49(6):397.

19. Evasovich MR, Clark TC, Horattas MC, et al. Does pneumoperitoneum during laparoscopy increase bacterial translocation? Surgical endoscopy. 1996; 1: 10(12):1176-9.

20. Zhang S, Du T, Jiang X, Song C. Laparoscopic appendectomy in children with perforated appendicitis: a meta-analysis. Surgical Laparoscopy Endoscopy \& Percutaneous Techniques. 2017; 1: 27(4):262-6. 